\title{
The effects of a physical exercise program on fetal well-being and intrauterine safety
}

\author{
Beata Makaruk ${ }^{1}$, Rafal Iciek $^{2} \mathbb{D}^{-}$, Andrzej Zalewski ${ }^{3}$, \\ Anna Galczak-Kondraciuk ${ }^{4}$ (D), Weronika Grantham ${ }^{1}$ (D) \\ ${ }^{1}$ Department of Sport for All, Faculty of Physical Education and Health in Biala Podlaska, \\ Jozef Pilsudski University of Physical Education, Warsaw, Poland \\ ${ }^{2}$ Department of Obstetrics and Women's Diseases, Karol Marcinkowski University of Medical Sciences, Poznan, Poland \\ ${ }^{3}$ Andrzej Zalewski's Specialist Practice, Biala Podlaska, Poland \\ ${ }^{4}$ Department of Health Promotion, Faculty of Physical Education and Health in Biala Podlaska, \\ Jozef Pilsudski University of Physical Education, Warsaw, Poland
}

\begin{abstract}
Objectives: The aim of this study was to evaluate the effects of a supervised physical exercise program on fetal well-being and intrauterine safety. Physical activity is recommended for healthy pregnant women. However, constant evaluation of fetal condition and development is recommended to ensure the safety of the exercise program.

Material and methods: Randomized control trial study design. Sixty-six healthy pregnant women (age 24-35) with singleton gestation were randomly assigned to either an exercise group ( $E G, n=34$ ) or a non-active control group (CG, $n=32)$. The exercise program included 81 sessions (moderate intensity, 3 times per week, 50-60 min/session from weeks 13 to weeks $40 / 41$ of pregnancy). Fetal well-being was assessed in weeks 32 and 37 of pregnancy. The cerebroplacental ratio (CPR) was calculated to evaluate the safety of the exercise program for the fetus.

Results: The differences in the CPR ratio measurements between EG and CG groups in week $37(p<0.05)$ were observed. The increase in the CPR ratio was also shown in week 37 of pregnancy in comparison to week $32(p<0.01)$. Moreover, maternal heart rate was significantly lower in the exercise group as measured at 37 weeks $(p<0.05)$.

Conclusions: The results of this study confirm that regular and supervised exercise program throughout pregnancy does not affect fetal well-being and is safe for the fetus. Additionally, regular physical activity improves maternal physical fitness and cardiac efficiency which might aid at preparing pregnant women for natural labor.
\end{abstract}

Key words: pregnancy; physical activity; regular exercise program; fetal safety; cerebroplacental ratio

Ginekologia Polska 2021; 92, 2: 126-131

\section{INTRODUCTION}

Pregnancy is a period in a woman's life when intense changes in her body occur. This requires continuous surveillance of both maternal and fetal well-being. Constant evaluation of uterine blood flows allows for the assessment of fetal health, development, and intrauterine safety [1]. The surveillance of fetal well-being is maintained through a detailed evaluation of blood flow velocity waveforms during noninvasive Doppler ultrasound examinations [2]. It is usually carried out throughout pregnancy, beginning from the end of the first trimester [3].

To determine fetal well-being or distress more accurately, cerebroplacental ratio (CPR) is used. CPR is defined as the ratio of middle cerebral artery pulsatility index
(MCA-PI) and the umbilical artery pulsatility index (UA-PI) [3]. CPR ratio is considered as a better indicator of hemodynamic changes and the cardiac output redistribution in the fetus, than the MCA-PI and UA-PI measurements alone [4]. CPR ratio is predictive for fetal health even in cases where the vascular resistance of the umbilical circulation seems to be normal [4]. CPR ratio below 1.04 might be symptomatic of centralization of fetal circulation, known as the brain-sparing effect, in which the blood is redistributed to the organs potentially most vulnerable to hypoxia, namely fetal central nervous system, heart, and adrenal glands $[3,5]$. CPR is also considered as more accurate at indicating the potential fetal hypoxia (as compared to the MCA-PI and UA-PI measurements alone) and generally correlates with 
potential perinatal risks. Moreover, it is indicative of a slight increase in placental resistance and a slight reduction in fetal cerebral resistance [3]. In routine clinical care, CPR is potentially the most indicative parameter of fetal intrauterine growth restriction (IUGR) or small-for-gestational-age fetuses (SGA) [6].

Fetal well-being may be associated with numerous lifestyle interventions. One of those interventions is physical exercise adapted specifically for pregnant women [1]. A training program should be individually designed and supervised by a qualified exercise specialist $[1,7]$. According to American College of Obstetricians and Gynecologists (ACOG) guidelines [1], the recommendation for pregnant women is to engage in physical activity for at least 20-30 mins/day with moderate intensity, on most (if not all) days of the week. However, ACOG emphasizes the lack of unequivocal data in the literature presenting the influence of regular exercise programs on fetal well-being, to assess the redistribution of oxygen, carbon dioxide, and nutrients through the placenta [1].

Several studies considered the influence of physical exercise on fetal well-being based upon a single bout of dynamic, submaximal exercise (usually cycle ergometer) [8-11]. The evaluation of individually advised regular exercise programs during pregnancy and their influence on maternal and fetal well-being in literature is still scarce [12-15]. To determine its safety, current and future research evaluating regular physical activity throughout pregnancy should include a multidimensional approach, examining intensity, duration, and type of exercises used as well as their influence on maternal and fetal blood flow measurements.

\section{Objectives}

The aim of this study was to evaluate the effects of a supervised and specifically designed complete physical exercise program on fetal well-being and intrauterine safety.

\section{MATERIAL AND METHODS} Participants

Eighty women with uncomplicated pregnancies were enrolled in this randomized controlled trial. Out of those, fourteen resigned because of personal reasons, before the start of the exercise program. Sixty-six healthy pregnant women (age 24-35 years), with no contraindications to exercise [1], and no clinical signs of IUGR or genetic defects, assessed at 11-14 weeks gestation [2], were finally included in this study. After providing informed written consent, eligible participants were randomly assigned to either the exercise group ( $E G, n=34$, mean age $27.55 \pm 1.70$ ) or non-active control group ( $C G, n=32$ mean age $27.55 \pm 1.70$ ). Women in the EG group, after the initial prenatal Doppler examination at weeks 11-14 [2], took part in an exercise
Table 1. Characteristics of both the exercise and the control groups

\begin{tabular}{|l|l|l|}
\hline Groups & EG (34) & CG (32) \\
\hline Maternal age, $y$ & $27.18 \pm 1.72$ & $27.55 \pm 1.70$ \\
\hline Maternal BMI kg/m & $21.5 \pm 0.5$ & $23.4 \pm 1.23$ \\
\hline Maternal body weight before birth $[\mathrm{kg}]$ & $73.5 \pm 3.8$ & $78.9 \pm 9.6$ \\
\hline Week of delivery & $39.8 \pm 0.4$ & $38.7 \pm 1.6$ \\
\hline Type of delivery N*/C* & $32 / 2$ & $18 / 16$ \\
\hline Birthweight, g & $3487 \pm 315$ & $3468 \pm 425$ \\
\hline Apgar Score $(0-10)$ & $9.94 \pm 0.348$ & $8.84 \pm 1.04$ \\
\hline
\end{tabular}

EG - exercise group; CG — non-active control group; ${ }^{*} \mathrm{~N}$ - normal delivery; ${ }^{*} \mathrm{C}$ - Cesarean delivery

program entitled 'Conscious 9 months'. The exercise program was initiated at 13 weeks gestation and continued until 40-41 weeks gestation. The CG group consisted of randomly assigned 32 healthy pregnant women. All participants also received routine prenatal care throughout pregnancy and were instructed not to participate in any other exercise programs. This study protocol was approved by the Bioethical Committee at the District Medical Chamber in Lublin, Poland. All the women were informed about the aims of the study and that they may discontinue the program at any time. Demographic characteristics of all the participant are presented in Table 1.

\section{Exercise program}

The exercise program included three 50-60 minutes training sessions per week (Monday, Wednesday, Friday). A total of 81 sessions were conducted. Adherence to the program in the EG was exceedingly high, with thirty-two out of thirty-four participants taking part in $100 \%$ of the training sessions. The remaining two participants missed only $1(98.8 \%)$ and 2 sessions (97.5\%) respectively. Hence, the overall adherence to the exercise program was $99.9 \%$.

Program intensity was moderate, with heart rate (HR) consistent between 100-145 beats per minute (individually advised).Women's HR was monitored during the training sessions, using HR monitor Polar M400, with a range of $15-240 \mathrm{bpm}$.

All training sessions included a warm-up (100-125 HRmin), core exercises (125-145 HRmin) and a cool down period (90-110 HRmin), which are described in detail in Table 2. Overall, all the sessions included breathing and relaxation techniques, antithrombotic exercises, strengthening exercises, stretching, pilates elements, and pelvic floor exercises.

To ensure maximum safety for both the mother and her fetus, all training sessions included 4-6 participants only, supervised by a qualified prenatal physical activity specialist (who was also the author of the program). Additionally, support from prenatal specialists, such as an obstetrician, a midwife, and a physiotherapist, was available to women at all times. 
Table 2. An example session of the 'Conscious 9 months' exercise program

\begin{tabular}{|c|c|c|}
\hline & EXERCISES & NOTES \\
\hline $\begin{array}{l}\text { Preparatory part } \\
\text { Warm-up 10-12 mins }\end{array}$ & $\begin{array}{l}\text { Sitting on the ball: } \\
\text { - finding the correct position } \\
\text { - spine mobility exercises } \\
\text { - short sequence: marching, step touch, side } \\
\text { lunge, forward lunge }\end{array}$ & $\begin{array}{l}\text { Exercise ball of the right size } \\
\text { Bare feet } \\
\text { Both sides }\end{array}$ \\
\hline $\begin{array}{l}\text { Dynamic stretching y } 2-3 \text { mins } \\
\text { ( } 8-12 \text { repetitions) }\end{array}$ & $\begin{array}{l}\text { Forward lunge: dynamic leg stretching } \\
\text { From sitting on a ball (wide-legged): } \\
\text { - lunge side stretches } \\
\text { — spine rolls (up and down) }\end{array}$ & Gentle stretching - both sides \\
\hline $\begin{array}{l}\text { Main part } \\
20-25 \text { mins } \\
\text { (repetitions: individually advised, suggested 6-12) } \\
\text { (repetitions: individually advised, suggested 6-12) }\end{array}$ & $\begin{array}{l}\text { Strengthening exercises on the ball (various } \\
\text { positions): } \\
\text { In sitting: } \\
\text { - squats and arm circles } \\
\text { - marching with spine rolls } \\
\text { - wide-legged sit:'crushing' the ball } \\
\text { - sitting with legs in front: lifting one foot at } \\
\text { a time and holding } \\
\text { In lying on the back: } \\
\text { - lifting the hips } \\
\text { - lifting the hips and heels } \\
\text { In lying on the side: } \\
\text { - kneeling: opening and closing the chest } \\
\text { (thoracic spine mobilization) with breathing } \\
\text { coordination } \\
\text { On hands and knees: } \\
\text { - lifting the legs } \\
\text { - press-ups } \\
\text { - lifting the arms, arm circles }\end{array}$ & $\begin{array}{l}\text { Strengthening exercises for main muscle } \\
\text { groups, intertwined with breathing exercises } \\
\text { and exercises for spine mobility } \\
\text { Maintaining breath awareness } \\
\text { As a variation: introducing balancing element } \\
\text { Both sides in all asymmetrical exercises }\end{array}$ \\
\hline $\begin{array}{l}\text { Finishing part } \\
\text { Stretching and relaxation } \\
12-15 \text { mins } \\
\text { (6-8 repetitions) }\end{array}$ & $\begin{array}{l}\text { Sitting on the knees, transitioning to kneeling } \\
\text { Kneeling with one leg straight: hip flexors } \\
\text { stretching } \\
\text { Wide-legged seated forward bend } \\
\text { Cross-legged seated forward bend and } \\
\text { opening the arms backward - chest opening } \\
\text { Relaxation } \\
\text { Lying supine on a medium soft ball, next to } \\
\text { a wall, feet together, knees open }\end{array}$ & $\begin{array}{l}\text { Both sides in asymmetrical exercise } \\
\text { During relaxation, blankets or cushions under } \\
\text { the knees } \\
\text { Relaxing music } \\
\text { In relaxation, the participants are covered with } \\
\text { blankets }\end{array}$ \\
\hline
\end{tabular}

\section{Fetal well-being}

Fetal well-being assessment included blood flow velocity measurement obtained by a VOLUSON 730 EXPERT color Doppler ultrasound system. Prenatal examinations were carried out in weeks 11-14 of gestation [2]. Fetal Doppler examinations were performed in both groups in weeks 32 and 37 and included the assessment of the pulsatility index (PI) in the middle cerebral artery (MCA) and in the umbilical artery (UA). This allowed for completion of a quantitative analysis of fetal blood flow velocities and resistance, as well as calculation of the CPR.

In the method used, the speed of blood flow is characterized by several indicators which express the level of pulsation of the curve of blood flow. Those indicators are based on the maximum Doppler wave shift of the blood flow in one cycle of a heartbeat. They express maximum speed in the systolic and diastolic phases of a heartbeat.

Doppler examinations were carried out according to the recommendations of the Fetal MedicineFoundation (FMF) [16] and the International Society of Ultrasound in Obstetrics and Gynecology (ISUOG) [17].

Additionally, fetal heart rate (FHR) and resistance index (RI) were measured.

\section{Statistical analysis}

The data are presented as group mean values \pm standard deviation (SD). The data were tested for normality of distribution using the Shapiro-Wilk test. A two-way (group $x$ time) repeated measurement ANOVA with Tukey post-hoc adjustments was used to compare the changes in the dependent variables inside the groups over the intervention period. Statistical significance was set at $p<0.05$. Statistica vs 13.1 program was used for all calculations.

\section{RESULTS}

Mean \pm SD values were measured in 32 and 37 weeks (Tab. 3). A significant interaction was observed as follows: group (EG, CG) $x$ time (32 and 37 weeks), CPR (F1,66 = 7.05; 


\begin{tabular}{|c|c|c|}
\hline Group & CPR 32 week & CPR 37 week \\
\hline EG & $1.78 \pm 0.34$ & $2.08 \pm 0.52^{* \wedge}$ \\
\hline CG & $1.80 \pm 0,33$ & $1.71 \pm 0.66$ \\
\hline
\end{tabular}

CG - control group; CPR - cerebroplacental ratio; EG - exercise group; ${ }^{*}$ statistical difference between the EG and CG $(p<0.05)$; ^statistically different from the value at week $32(p<0.01)$

\begin{tabular}{|c|c|c|}
\hline Group & MCA PI Week 32 & MCA PI Week 37 \\
\hline EG & $1.86 \pm 0,27$ & $1.63 \pm 0.34^{* \wedge}$ \\
\hline CG & $1.91 \pm 0,27$ & $1.42 \pm 0.37$ \\
\hline
\end{tabular}

CG - control group; EG - exercise group; * statistical difference between the EG and CG $(p<0.05) ; \wedge$ statistically different from the value at week $32(p<0.01)$

\begin{tabular}{|c|c|c|}
\hline Groups & MCA RI Week 32 & MCA RI Week 37 \\
\hline EG & $0.83 \pm 0.05$ & $0.79 \pm 0.08^{*} \wedge$ \\
\hline CG & $0.84 \pm 0.05$ & $0.74 \pm 0.10$ \\
\hline
\end{tabular}

$C G$ - control group; $E G$ - exercise group; *statistical difference between the EG and CG $(p<0.05) ; \wedge$ statistically different value from the value at week $32(\mathrm{p}<0.05)$

$\mathrm{p}<0.01, \mathrm{np} 2=0.097), \mathrm{np} 2=0.097$. The CPR cerebroplacental ratio difference was statistically significant between $E G$ and CG groups at 37 weeks $(p<0.5)$. Moreover, CPR increased in week 37 as compared to week 32.

Moreover, a significant interaction was observed between groups (EG, CG) $x$ time (32 and 37 weeks), MCA PI $(F 1,66=5.60 ; p<0.05, \eta p 2=0.078)$. The MCA PI parameter difference was statistically significant between EG and CG groups at 37 weeks $(p<0.05)$, which can be seen in Table 4 .

There was also another significant interaction observed as follows: group (EG, CG) $x$ time (32 and 37 weeks), MCA RI $(F 1,66=6.52 ; p<0.05, \eta p 2=0.089)$. The MCA RI parameter difference was statistically significant between EG and CG groups at 37 weeks $(p<0.05)$, which can be seen in Table 5 .

Furthermore, there was no significant interaction between groups (EG, CG) x time (32 and 37 weeks), in UA-PI (F1,66 = 0.86; $\mathrm{p}>0.05, \eta \mathrm{p} 2=0.012)$. The UA-PI parameter difference was not statistically significant between EG and CG groups at 32 and 37 weeks ( $p>0.05)$, which can be seen in Table 6 .

There was also no significant interaction between groups (EG, CG) x time (32 and 37 weeks), in UA-RI (F1,66 = 1.33; $p>0.05, \eta p 2=0.019)$. The UA-RI parameter difference was not statistically significant between EG and CG groups at 32 and 37 weeks $(p>0.05)$, which can be seen in Table 7 .
Table 6. UMBA PI values (mean \pm SD) in the exercise group and the non-active control group

\begin{tabular}{|l|l|l|}
\hline Groups & UMBA PI Week 32 & UMBA PI Week 37 \\
\hline EG & $1.05 \pm 0.18$ & $0.79 \pm 0.09$ \\
\hline CG & $1.10 \pm 0.18$ & $0.88 \pm 0.23$ \\
\hline
\end{tabular}

CG — control group; EG - exercise group

Table 7. UMBA RI values (mean \pm SD) in the exercise group and the non-active control group

\begin{tabular}{|l|l|l|}
\hline Groups & UMBA RI Week 32 & UMBA RI Week 37 \\
\hline EG & $0.64 \pm 0.08$ & $0.57 \pm 0.07$ \\
\hline CG & $0.68 \pm 0.08$ & $0.59 \pm 0.11$ \\
\hline
\end{tabular}

CG - control group; EG - exercise group

\begin{tabular}{|c|c|c|}
\hline Groups & FHR Week 32 & FHR Week 37 \\
\hline EG & $138.33 \pm 8.51$ & $136.45 \pm 6.86^{*} \wedge$ \\
\hline CG & $142.57 \pm 6.27$ & $147.43 \pm 7.35$ \\
\hline
\end{tabular}

CG - control group; EG - exercise group; FHR — fetal heart rate; *statistical difference between the EG and CG $(p<0.05)$; $\wedge$ statistically different value from the value at week $32(p<0.05)$

In addition, a significant interaction was observed as follows: group ( $E G, C G) x$ time (32 and 37 weeks), maternal $\mathrm{HR}(\mathrm{F} 1,66=7.34 ; \mathrm{p}<0.05, \mathrm{np} 2=0.100)$. The HR parameter difference was statistically significant between EG and CG groups at 37 weeks $(p<0.05)$, which can be seen in Table 8 .

\section{DISCUSSION}

The aim of this study was to evaluate the effects of a regular complete physical exercise program in the course of pregnancy on fetal well-being and intrauterine safety. To assess fetal well-being and safety, Doppler examinations were used, allowing for non-invasive evaluation of fetal hemodynamic changes and the degree of flow resistance $[6,18-21]$.

The results of this study present that during 27 weeks of this experiment, neither fetal hypoxia, growth retardation, placental exchange nor amniotic fluid volume abnormalities were observed in any of the fetuses, which is consistent with previous research [22-24]. The results of this trial are in accordance with the results of other studies, presenting that regular moderate physical activity program in pregnancy is not posing any health risks neither to the mother nor to the fetus [1, 12-15].

The results confirm no adverse influence of physical exercise on fetal well-being both in weeks 32 and 37 . In week 32 the CPR ratio was within its normal range in both groups, 
which indicates that maternal physical exertion as part of the exercise program had no effect on the fetus. Similarly, in week 37, the CPR ratio was also within norms, showing no adverse effect on fetal health. Importantly, CPR is seen to be a more effective parameter of fetal hemodynamic changes, as well as the cardiac output and blood flow redistribution of the fetus, than the MCA-PI and UA-PI measurements alone [4]. Several other studies assessed fetal well-being based upon the above-mentioned parameters alone, which defines the vascular resistance in the progress of blood flow, measuring this flow in the tested vessel [11, 25-27], which is not as accurate.

In this field, some studies are based on surveys and questionnaires in which pregnant women evaluate their physical activity subjectively $[14,28,29]$. Clearly, this method has clinical limitations. Moreover, the choice of exercises (their intensity, duration, and type) to determine physical activity's influence on a woman's body, still remains to be examined in further studies $[11,30]$. Little data is available on physical activity in the course of pregnancy.

Barakat et al. [12] suggested that more research is needed on specifically designed regular exercise programs, including exercise guidelines and safety.

Fetal well-being assessment for this study included blood flow velocity measurements obtained by a color Doppler ultrasound system. UA and MCA were examined. The analysis of blood flow was based on the shape of the Doppler wave shift and the assessment of the PI in the MCA and in the UA.

The results show there was a slight decrease in both the MCA-PI and MCA-RI parameters, which are normal physiological mechanisms in an uncomplicated pregnancy. Hence, in both groups in weeks 32 and 37 , this decrease was comparable and within a normal range.

The exercise program did not significantly influence fetal umbilical artery flow parameters. In weeks 32 and 37, the PI and RI parameters did not differ significantly or clinically in both exercise and control groups. Additionally, the dynamics of $\mathrm{PI}$ and $\mathrm{RI}$ decrease was comparable in both groups and was within normal range with the progression of pregnancy.

All of those further confirm that the exercise program did not adversely affect the fetus, as examined by Doppler ultrasound.

Additionally, the described regular exercise program had a positive effect on maternal HR in week 37. HR was significantly lower in the exercise group, which is not in line with the current research [31-35]. This result can indicate general improvement of maternal physical fitness and cardiac efficiency. It might also serve as an important factor in preparation for normal labor.

The innovation of this study, next to the use of CPR ratio, lies also in the intervention used. The exercise program was complete and rounded, included various elements, not generally available to pregnant women in routine care. Moreover, the program was individually designed, aimed at preparing women towards labor and led by an experienced prenatal exercise specialist, who continually communicated with medical personnel, ensuring maximum safety for both mother and fetus. This also had its impact on ensuring an exceedingly high adherence of the participants to the exercise program.

\section{CONCLUSIONS}

The results of the current experiment confirm that the specifically designed regular exercise program 'Conscious 9 months' (taking into consideration specific types, intensities, and duration parameters) does not pose a risk to fetal well-being and is safe for the fetus.

Additionally, the program described positively affected maternal HR in the exercise group, indicating potentially improved maternal physical fitness and cardiac efficiency, which may significantly influence normal labor.

\section{Conflicts of interest}

The authors declare that they have no competing interests, financial or otherwise.

\section{Funding}

This study was conducted thanks to the Youth Activity project at the Jozef Pilsudski University of Physical Education in Warsaw, Faculty of Physical Education and Sport in Biala Podlaska, - MN. IV/4 - financed by the Ministry of Science and Higher Education.

\section{REFERENCES}

1. Physical Activity and Exercise During Pregnancy and the Postpartum Period. Obstetrics \& Gynecology. 2020; 135(4): e178-e188, doi: 10.1097/aog.0000000000003772.

2. zespół z. Polish Gynecological Society - Ultrasound Section Guidelines on ultrasound screening in gynecology - 2015. Polish Gynaecology. 2015; 86(8): 635-639, doi: 10.17772/gp/58975.

3. Ebbing $C$, Rasmussen $\mathrm{S}$, Kiserud T. Middle cerebral artery blood flow velocities and pulsatility index and the cerebroplacental pulsatility ratio: longitudinal reference ranges and terms for serial measurements. UItrasound Obstet Gynecol. 2007; 30(3): 287-296, doi: 10.1002/uog.4088, indexed in Pubmed: 17721916.

4. Palacio M, Figueras F, Zamora $L$, et al. Reference ranges for umbilical and middle cerebral artery pulsatility index and cerebroplacental ratio in prolonged pregnancies. Ultrasound Obstet Gynecol. 2004; 24(6): 647-653, doi: 10.1002/uog.1761, indexed in Pubmed: 15517536.

5. Gómez O, Figueras F, Fernández $\mathrm{S}$, et al. Reference ranges for uterine artery mean pulsatility index at 11-41 weeks of gestation. Ultrasound Obstet Gynecol. 2008; 32(2): 128-132, doi: 10.1002/uog.5315, indexed in Pubmed: 18457355.

6. Figueras F, Fernández S, Hernández-Andrade E, et al. Umbilical venous blood flow measurement: accuracy and reproducibility. Ultrasound Obstet Gynecol. 2008; 32(4): 587-591, doi: 10.1002/uog.5306, indexed in Pubmed: 18618412

7. Wrońska A, Szumielewicz A. Przeciwwskazania do prenatalnej aktywności fizycznej a poziom wiedzy przyszłych instruktorów rekreacji ruchowej [Contraindications for prenatal physical activity and the level of knowledge of future exercise instructors]. Ogrody Nauk i Sztuk. 2015; 5: 317-23. 
8. Carpenter MW, Sady SP, Hoegsberg B, et al. Fetal heart rate response to maternal exertion. JAMA. 1988; 259(20): 3006-3009, indexed in Pubmed: 3285041.

9. Veille $J C$, Bacevice $A E$, Wilson $B$, et al. Umbilical artery waveform during bicycle exercise in normal pregnancy. Obstet Gynecol. 1989; 73(6): 957-960, doi: 10.1097/00006250-198906000-00010, indexed in Pubmed: 2657527.

10. Manders MA, Sonder GJ, Mulder EJ, et al. The effects of maternal exercise on fetal heart rate and movement patterns. Early Hum Dev. 1997; 48(3): 237-247, doi: 10.1016/s0378-3782(96)01858-0, indexed in Pubmed: 9154415.

11. Ertan AK, Schanz S, Tanriverdi HA, et al. Doppler examinations of fetal and uteroplacental blood flow in AGA and IUGR fetuses before and after maternal physical exercise with the bicycle ergometer. J Perinat Med. 2004; 32(3): 260-265, doi: 10.1515/JPM.2004.049, indexed in Pubmed: 15188802.

12. Barakat R, Pelaez $M$, Montejo R, et al. Exercise throughout pregnancy does not cause preterm delivery: a randomized controlled trial. J Phys Act Health. 2014; 11(5): 1012-7.

13. Haakstad LAH, Bø K. Effect of regular exercise on prevention of excessive weight gain in pregnancy: a randomised controlled trial. Eur J Contracept Reprod Health Care. 2011; 16(2): 116-125, doi: 10.3109/13625187.2011.560307, indexed in Pubmed: 21417561.

14. de Oliveria Melo AS, Silva JL, Tavares JS, et al. Effect of a physical exercise program during pregnancy on uteroplacental and fetal blood flow and fetal growth: a randomized controlled trial. Obstet Gynecol. 2012; 120(2 Pt 1): 302-310, doi: 10.1097/AOG.0b013e31825de592, indexed in Pubmed: 22825089.

15. Perales $\mathrm{Sa}$, Mateos $\mathrm{S}$, Vargas $\mathrm{M}$, et al. Fetal and maternal heart rate responses to exercise in pregnant women. A randomized controlled trial. Arch Med Deporte. 2015; 32: 361-7.

16. Nicolaides $\mathrm{KH}$. The $11-13+6$ weeks scan. Fetal Medicine Foundation London. ; 2004: 1-112.

17. Bhide A, Acharya G, Bilardo CM, et al. ISUOG practice guidelines: use of Doppler ultrasonography in obstetrics. Ultrasound Obstet Gynecol. 2013; 41(2): 233-239, doi: 10.1002/uog.12371, indexed in Pubmed: 23371348.

18. Najafzadeh A, Dickinson JE. Umbilical venous blood flow and its measurement in the human fetus. J Clin Ultrasound. 2012; 40(8): 502-511, doi: 10.1002/jcu.21970, indexed in Pubmed: 22855424.

19. Magann EF, Sandlin AT, Ounpraseuth ST. Amniotic fluid and the clinical relevance of the sonographically estimated amniotic fluid volume: oligohydramnios. J Ultrasound Med. 2011; 30(11): 1573-1585, doi: 10.7863/jum.2011.30.11.1573, indexed in Pubmed: 22039031.

20. Rytlewski K, Kusmierska K, Howczak J. Zaburzenia przepływu łożyskowego - praktyczne zastosowanie kliniczne [Feto-placental blood flow--practical remarks]. Przegl Lek. 2009; 66(7): 394-402.

21. Senat MV, Nizard J. [Contribution of Doppler exploration of ductus venosus flow]. J Gynecol Obstet Biol Reprod (Paris). 2002; 31(1 Suppl): 2S64-9, indexed in Pubmed: 11973522.

22. Monga $M$, Brenner IK, Wolfe LA, et al. Physical conditioning effects on fetal heart rate responses to graded maternal exercise. Med Sci Sports
Exerc. 1999; 31(6): 792-799, doi: 10.1097/00005768-199906000-00006, indexed in Pubmed: 10378905.

23. Davies GAL, Wolfe LA, Mottola MF, et al. Society of Obstetricians and gynecologists of Canada, SOGC Clinical Practice Obstetrics Committee. Joint SOGC/CSEP clinical practice guideline: exercise in pregnancy and the postpartum period. Can J Appl Physiol. 2003; 28(3): 330-341, indexed in Pubmed: 12955862.

24. Wiebe HW, Boulé NG, Chari R, et al. The effect of supervised prenatal exercise on fetal growth: a meta-analysis. Obstet Gynecol. 2015; 125(5): 1185-1194, doi: 10.1097/AOG.0000000000000801, indexed in Pubmed: 25932847.

25. Okido MM, Magario FA, Berezowski AT, et al. Repercussões agudas do exercício físico materno sobre os parâmetros hemodinâmicos útero-placentários e fetais [Impact of acute maternal exercise on uteroplacental and fetal hemodynamics patterns]. Femina. 2010; 38(11): 607-12.

26. Szymanski LM, Satin AJ. Exercise during pregnancy: fetal responses to current public health guidelines. Obstet Gynecol. 2012; 119(3): 603-610, doi: 10.1097/AOG.0b013e31824760b5, indexed in Pubmed: 22314872.

27. Bauer PW, Broman CL, Pivarnik JM. Exercise and pregnancy knowledge among healthcare providers. J Womens Health (Larchmt). 2010; 19(2): 335-341, doi: 10.1089/jwh.2008.1295, indexed in Pubmed: 20113144.

28. Harris ST, Liu J, Wilcox S, et al. Exercise during pregnancy and its association with gestational weight gain. Matern Child Health J. 2015; 19(3): 528-537, doi: 10.1007/s10995-014-1534-8, indexed in Pubmed: 24912945.

29. Clapp JF. Fetal heart rate response to running in midpregnancy and late pregnancy. Am J Obstet Gynecol. 1985; 153(3): 251-252, doi: 10.1016/s0002-9378(85)80106-X, indexed in Pubmed: 4050891.

30. Alves JA, Silva BY, de Sousa PC, et al. Reference range of uterine artery Doppler parameters between the 11th and 14th pregnancy weeks in a population sample from Northeast Brazil. Rev Bras Ginecol Obstet. 2013;35(8): 357-362, doi: 10.1590/s0100-72032013000800004, indexed in Pubmed: 24126354.

31. May LE, Suminski RR, Berry A, et al. Regular maternal exercise dose and fetal heart outcome. Med Sci Sports Exerc. 2012; 44(7): 1252-1258, doi: 10.1249/MSS.0b013e318247b324, indexed in Pubmed: 22217566.

32. May LE, Suminski RR, Langaker MD, et al. Regular maternal exercise dose and fetal heart outcome. Med Sci Sports Exerc. 2012; 44(7): 1252-1258, doi: 10.1249/MSS.0b013e318247b324, indexed in Pubmed: 22217566.

33. May LE, Glaros A, Yeh HW, et al. Aerobic exercise during pregnancy influences fetal cardiac autonomic control of heart rate and heart rate variability. Early Hum Dev. 2010; 86(4): 213-217, doi: 10.1016/j.earlhumdev.2010.03.002, indexed in Pubmed: 20356690.

34. Van Leeuwen P, Gustafson KM, Cysarz D, et al. Aerobic exercise during pregnancy and presence of fetal-maternal heart rate synchronization. PLoS One. 2014; 9(8): e106036, doi: 10.1371/journal.pone.0106036, indexed in Pubmed: 25162592.

35. Gustafson KM, May LE, Yeh Hw, et al. Fetal cardiac autonomic contro during breathing and non-breathing epochs: the effect of maternal exercise. Early Hum Dev. 2012; 88(7): 539-546, doi: 10.1016/j.earlhumdev.2011.12.017, indexed in Pubmed: 22264436. 